Osteonecrosis mandibular por bisfosfonato intravenoso

\section{Bisphosphonate-related osteonecrosis of the jaw}

Sr. Editor: La osteonecrosis de mandíbula por bisfosfonatos (ONMB) se define como un área expuesta de hueso maxilar, que en 8 semanas no cura, en un paciente tratado con bisfosfonatos (BF) y que no ha recibido terapia radiante ${ }^{1}$. El diagnóstico es principalmente clínico. Se ignora el mecanismo por el cual se produce la necrosis, aunque se hayan planteado múltiples hipótesis, considerando que sería gatillado en algunos casos por la extracción de piezas dentarias ${ }^{1}$. La ONMB se ha descrito con mayor frecuencia con la utilización de BF endovenosos y son crecientes los reportes con BF vía oral.

Una paciente de 72 años fue internada en el Hospital Británico con antecedente de adenocarcinoma de mama derecha, tratada quirúrgicamente con cuadrantectomía y vaciamiento axilar en el año 2003. Presentó metástasis óseas en el 2004, para lo cual recibió tratamiento radioterápico. Recibió tamoxifeno junto con pamidronato mensual durante dos años, con una dosis acumulativa de $2.160 \mathrm{mg}$. Ingresó en septiembre del año 2006 por presentar dolor en el cuerpo derecho del maxilar inferior, con lesión osteolítica en dicha localiza-

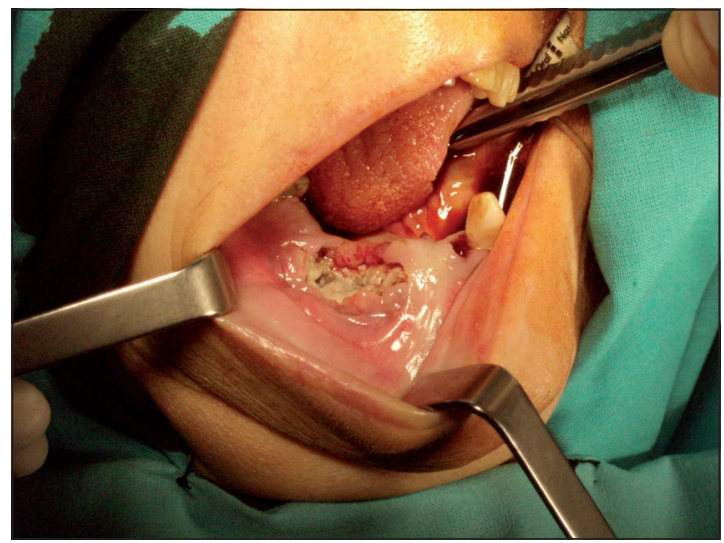

Figura 1. Úlcera intraoral extensa que deja expuesta parte del cuerpo de la mandíbula, en el que aparece sólo el segundo molar inferior derecho. ción. Un mes antes del comienzo del dolor se le habían extraído piezas dentarias. No había recibido radioterapia en dicha área. El único hallazgo positivo en el examen físico fue la exposición del cuerpo derecho del maxilar inferior, con pérdida de piezas dentarias (Figura 1). En la radiografía del cuerpo mandibular del lado derecho (Figura 2) se observó un área de osteolisis y trazo de fractura. La tomografía axial computada del macizo facial mostró alteración ósea y alteración de partes blandas por fuera y por dentro de la rama del maxilar inferior, junto con engrosamiento del seno maxilar derecho. Se realizó biopsia de la lesión, en la que se descartó presencia de células neoplásicas, evidenciándose trabéculas óseas desvitalizadas e inflamación subaguda con necrosis. Se realizó exodoncia de piezas 18,19 y 12 , esperando la delimitación espontánea del proceso, e irrigación con clorhexidina $0,12 \%$. A pesar del tratamiento conservador, la paciente presentó dolor severo y supuración por lo cual en marzo de 2007 se realizó resección parcial del maxilar inferior derecho, sin reconstrucción ósea. Se discontinuó el tratamiento con BF. A pesar de que esta cirugía fue exitosa con control del proceso, la paciente tuvo progresión de su enfermedad de base y falleció meses después.

Los BF inducen la apoptosis de osteoclastos, además de producir una alteración en la proliferación celular osteoclástica². Se ha demostrado, además, que los BF presentan propiedades

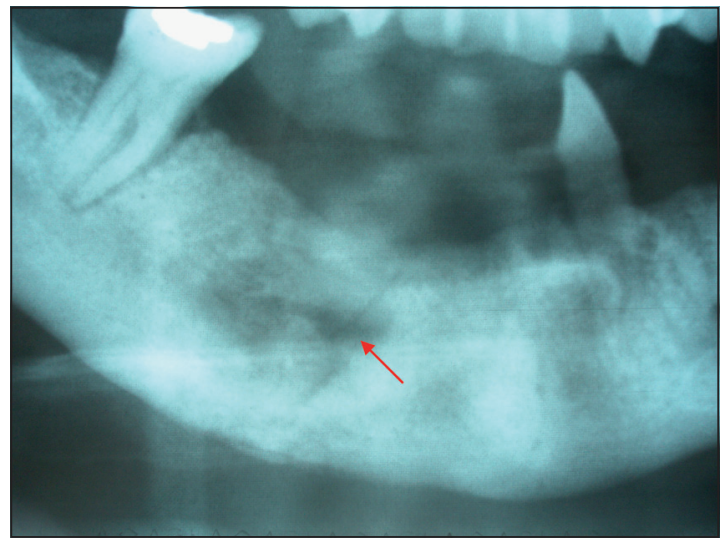

Figura 2. Radiografía del cuerpo mandibular del lado derecho, con área de osteolisis y trazo de fractura (flecha). 
antiangiogénicas ${ }^{3}$. Desde 2003 se han reportado casos de ONMB secundaria a pamidronato y zoledronato, en pacientes con mieloma, cáncer de mama, testículo, pulmón, próstata, sarcoma uterino, leucemia mieloide crónica post trasplante de precursores hematopoyéticos y en osteoporosis $\sin$ malignidad ${ }^{1-3}$. La mayoría de los casos de osteonecrosis se presentan después de una extracción dental $(78 \%)$, infección u otro proceso y sólo una minoría (14\%) aparece espontáneamente 3 . Suelen ser unilaterales ${ }^{4}$. El plazo de aparición va desde 4 meses del inicio del tratamiento, hasta alcanzar $10 \%$ de los pacientes tratados durante 36 meses $^{1-4}$. En una revisión reciente, incluyendo 368 casos, $65 \%$ presentó compromiso mandibular, 26\% maxilar y 9\% ambos; un tercio eran asintomáticos. El compromiso multifocal es más frecuente en el maxilar superior. Hasta en $60 \%$ de los casos ocurrió posterior a un procedimiento odontológico. El 94\% recibió BF endovenosos y $85 \%$ tenían mieloma múltiple o carcinoma de mama metastático ${ }^{3}$. La mandíbula se afecta 2 a 3 veces más que el maxilar ${ }^{3,4}$. La presentación típica de esta complicación consiste en un área de hueso necrótico expuesto, que puede ser el sitio de una infección secundaria. Como complemento del diagnóstico se encuentran las imágenes: la más utilizada es la panorámica de maxilar, seguida de la tomografía y el centelleograma. Los factores de riesgo más importantes para el desarrollo de esta complicación son la potencia del BF (zolendronato $>$ pamidronato $>\mathrm{BF}$ orales), la dosis total de $\mathrm{BF}$ y la duración del tratamiento, así como los antecedentes de trauma, procedimiento odontológico o infección dentaria. Otros factores son: edad, raza caucásica, pobre higiene y diabetes. No existe una estrategia terapéutica exitosa. Todo paciente en tratamiento con BF o que va a comenzarlo, deberían recibir asesoramiento odontológico. Toda enfermedad períodontal o dental debería ser adecuadamente tratada previo al inicio del tratamiento con BF. Se recomienda higiene oral y asesoramiento odontológico periódico, evitando la cirugía dental durante la terapia. Si fuera necesaria, se recomienda un abordaje conservador, no quirúrgico, con medidas locales, como debridamiento superficial, bacteriostáticos locales, asociados a antibióticos sistémicos, dentro de los cuales la clindamicina y las fenoximetilpenicilinas han demostrado tener resultados satisfactorios por 2 a 3 semanas ${ }^{2}$. Kademani y cols ${ }^{5}$ proponen realizar un injerto que cubra el hueso remanente cuando hay gran disrupción de los tejidos blandos. En cambio, cuando la ONMB es grave, el enfoque conservador no es útil y proponen resección de la mandíbula afectada, sin reconstrucción ósea ${ }^{6}$. En la serie de Ruggiero y cols ${ }^{3}$, la gran mayoría de los 63 casos requirió abordaje quirúrgico, logrando márgenes quirúrgicos con hueso sangrante, y lo recomiendan en pacientes sintomáticos o con infección concomitante. Recientemente, la Asociación Americana de Cirujanos Maxilofaciales clasificó las ONMB en tres estadios, lo que tiene implicancias prácticas en el tratamiento y pronóstico: estadio 1: hueso necrótico expuesto en pacientes asintomáticos y sin evidencia de infección; estadio 2: hueso necrótico expuesto en pacientes con dolor y evidencia de infección; y estadio 3: hueso necrótico expuesto en pacientes con dolor y evidencia de infección, y uno o más de los siguientes: fractura patológica, fístula extra-oral, u osteolisis que se extiende al borde inferior ${ }^{7}$. En los primeros dos estadios el manejo es conservador y en el tercero suele ser quirúrgico. No existen datos suficientes que apoyen la suspensión del tratamiento con BF, si bien existen reportes anecdóticos de resolución completa de la osteonecrosis meses después de la discontinuación de los mismos ${ }^{3}$. La ONMB supone una importante comorbilidad, con una incidencia creciente, y que altera la calidad de vida. A pesar de ello, estos pacientes fallecen de su enfermedad de base y no de ONMB.

Pablo Young ${ }^{1}$, Bárbara C. Finn ${ }^{1}$, Roque S. Adan $^{2}$, Julio E. Bruetman ${ }^{1}$, Juan S. Lasa ${ }^{1}$. Servicios de ${ }^{1}$ Clínica Médica, ${ }^{2}$ Cirugía de Cabeza y Cuello, Hospital Británico de Buenos Aires, Argentina.

\section{Referencias}

1. Migliorati CA, Siegel MA, Elting L. Bisphosphonateassociated osteonecrosis: a long- term complication of bisphosphonate treatment. Lancet Oncol 2006; 7: 50814.

2. Marx R, Sawatari Y, Fortin M, Broumand V. Bisphosphonate-Induced Exposed Bone (Osteonecrosis/ Osteopetrosis) of the Jaws: Risk Factors, Recognition, Prevention and Treatment. J Oral Maxillofac Surg 2005; 63: 1567-75. 
3. Woo SB, Hellstein J, Kalmar JR. Systematic Review: Bisphosphonates and Osteonecrosis of the Jaws. Ann Intern Med 2006; 144: 753-61.

4. Ruggiero SL, Mehotra B, Rosenberg T, Engroff SL. Osteonecrosis of the Jaws Associated With the Use of Bisphosphonates: A Review of 63 Cases. J Oral Maxillofac Surg 2004; 62: 527-34.

5. Kademani D, Koka S, Lacy MQ, Rajkumar SV. Primary Surgical Therapy for Osteonecrosis of the Jaw Secondary to Bisphosphonate Therapy. Mayo Clin Proc 2006; 81: 1100-3.
6. Bilezikian JP. Osteonecrosis of the Jaw- Do Bisphosphonates Pose a Risk? N Engl J Med 2006; 355: 2278-81.

7. Thumbigere-Math V, Sabino MC, Gopalakrishnan R, Huckabay S, Dudek AZ, Basu S, et al. Bisphosphonaterelated osteonecrosis of the jaw: clinical features, risk factors, management, and treatment outcomes of 26 patients. J Oral Maxillofac Surg 2009; 67: 1904-13.

\section{Correspondencia a:}

Pablo Young

E-mail: pabloyoung2003@yahoo.com.ar 